\title{
The Specific Methods Study of Landscape Rebirth Design of Coal Mining Wastelands Under the Theoretic Direction of Modern Landscape Planning
}

\author{
Fuyan $\mathrm{Yu}$ \\ School of Art and Design \\ Huanghe Science and Technology College \\ Zhengzhou, China
}

\begin{abstract}
This essay, with the methods of document research, field survey, analysis and summary and others, makes a conclusion of the key element of coal mine wasteland rebirth, establishes the basic principles of landscape design, discusses and summarizes the specific methods of landscape rebirth design. In the meanwhile of theory summary, the essay learns from the valuable experiences of mines reconstruction projects and industrial wasteland renovation projects home and abroad, takes into consideration of mines wasteland environmental resources structure, reaches a design mode of landscape rebirth of wasteland through the ways of reasonable reservation, reconstruction, reuse of wasteland elements.
\end{abstract}

Keywords-Coal mining wastelands; Landscape rebirth design; Ecological restoration

\section{INTRODUCTION}

According to incomplete statistics, the areas of subsiding lands have been 4,000-6,600 square kilometers due to the excessive coal mining and still increases in about 200square kilometers every year through the country. With the acceleration of urbanization, the subsiding lands gradually becomes part of the urban development parcels, but the subsiding lands, polluted natural environment, industrial mines needing reconstruction and like that become obstacles of urban space development.

The landscape renovation study should be started from the transformation of aesthetics recognition, in the traditional aesthetics theory it is believed that the landscape and equipment of wastelands are ugly, all should be removed from the ground and all the damaged should be restored the same as it was before. While in the post -industrial landscape theory, the industrial ruins in the wastelands, looking like the Earth work, are the artwork left on the earth by industrial production. Rusted, abandoned industrial plants and equipment no longer represents the dirty, ugly, ruined and negative things. On the contrary, they are the cultural landscapes left in the human's history, the testimony of human's industrial civilization. It has been a difficult task to harmonize the traditional landscapes and modern industrial landscapes in dealing with the problem of

Fund project: Soft Science Research Project 2014 of Technology Bureau of Zhengzhou City, "The Strategy and Study on Landscape Regeneration Design and Updating and Utilization of Abandoned Coal Mine Area in Zhengzhou”, project number: 20141110 landscape reconstruction of wastelands.

\section{THE PRINCIPLES OF LANDSCAPE DESIGN OF COAL MINING WASTELANDS}

\section{A. Ecological principle}

According to the ecological trend, more and more landscape designers begin to respect ecology. In the landscape design, materials made of the renewable resources are used as many as possible, the materials on the ground are recycled to fulfill their potential so that the resources consumed in production, processing, transporting materials and the waste in construction can be reduced without the loss of local cultural characteristics. The original buildings and equipment on the ground can have new use function if fully used. Water is used efficiently to reach the reduction of water consumption. The renewable resources are relied on through use of sunlight, natural ventilation and river water. Local materials are used especially the native plants to respect natural renewable vegetation. The construction should conform to the local natural conditions with reasonable use of soil, vegetation and other natural resources. All of these should reflect natural elements and process in construction with less man-made traits, lay emphasis on protection of ecosystem, preservation and establishment of biological diversity.

\section{B. Context principle}

$\mathrm{Yu}$ Kongjian believes the current domestic human settlement environment is faced with two threats. Firstly, there arises crisis between land and human beings which are shown as common man-made pollution, the deterioration of desertification and others. Secondly, China are confronted with cultural infiltration, cultural aggression, cultural replacement, and gradually loses the essences of Chinese culture. "If we do not start paying attention to these problems, our future generations will have no possibilities to look back to their national history and find a spiritual conversion of their spirits".

The urban wastelands are reminders of people's memory in this age, the true carriers for city's history. The essence of landscape renovation of urban wastelands is to preserve city's history, ensure the truthfulness of its historical 
remains and traditional culture. The truthfulness of wastelands landscape must be realized on the basis of full research of the landscape of original ground: studying the historical background and cultural values of its surroundings, and then selecting and keeping the main characteristics which should be emphasized on while the non-major characteristics should be dealt with flexibly according to the specific design.

\section{Economical Principle}

The landscape design should keep economical principle. If people only pursue the economic benefits without consideration of possibility of natural resources' exhaustion, the resources of economy development will disappear just like the Rur Industrial Base. As the resources dry up, city will lose its sources of economic development and its past living environment will not develop, therefore it will gradually decline. The conventional governance model separates environment protection with economic development, thus the coal mining is explored without considering the economic development.

\section{Artistic Principle}

The landscape design of coal mining wastelands should follow the artistic principle of learning from nature. In design, the overall layout and distribution should conform to nature, every landscape spectacle should be combined according to natural laws for the pursuit of natural and rustic charm. The design should pay attention to proportion and scale, contrast and harmony, symmetry and equilibrium, cadence and rhythm, comparison and association.

\section{THE APPLICATION OF LANDSCAPE REBIRTH DESIGN OF COAL MINING WASTELANDS}

In the process of landscape rebirth design of coal mining wastelands, landscape designer' $s$ task is to deal with these coal mining landscape abandoned by people which once had glorious history but seriously destroyed local ecological environment by the application of various design methods and approaches combing science and art in order to achieve the purpose of ecological restoration, environment renewal, culture reconstruction and economic development. On the basis of inheriting the coal mining landscape, people transform the decaying coal mining wastelands into landscape with multiple meanings.

Getting some revelations from domestic and overseas successful cases, designers make a conclusion of design methods of those cases that are mainly these ways including dealing with deserted mining facilities, handling surface traces after industrial production, disposing of pollutant, transforming and reusing abandoned pits, designing landscape of plan and learning from building arts of Chinese classical gardens.

\section{A. Dealing with abandoned mining facilities}

The abandoned mining facilities include deserted buildings, structures, equipment, storage facilities and so on. It will take large amount of money if they all are torn down. Therefore, all or parts of them can be kept as a part of the site. Generally, they can be handled with the following ways:

\section{1) Overall retention}

Retaining all including ground, underground structures, equipment, road network, function areas and others, people should only renew the parts which have bad effect on landscape. This kind of handing method are mainly applied in innovation of wastelands of urban residential areas.

\section{2) Partial retention}

People can remain some parts of the original abandoned industrial landscape, make them the iconic landscape. The remaining parts could be the meaningful industrial landscape with characteristics of site such as abandoned pits, cliffs and like that, as well as the industrial buildings with long history or old high quality buildings.

\section{3) Retention of components}

Parts of buildings or structures like walls, frames and others are reserved, from which people can see once industrial landscape

\section{4) Reuse of waste things}

There are two major ways to handle the waste material in the coal mining wastelands. The first one is to use the industrial waste and make it the unique landscape design materials. The other one is to reuse the waste material after reworking it, for example, the steel plate can be melt and cast into facilities, bricks and stones can be ground up as concrete aggregates, the rubble which is left after buildings are dismantled can be used as filling materials in the site.

\section{B. Handling the surface traces after industrial production}

The industrial production has left traces such as sands, chunks and others like that. In landscape reconstruction, many designers don't try to hide or wipe out those traces but respect the characteristics of the site and keep them with the ways such as reservation, artistic reworking and so on. Among the design ways, the one of earth artists' works are outstanding. Their concern for nature and ecology are expressed clearly in this special site of mining wasteland. Their design methods of lifting the value of landscape of mining wastelands through artistic production is worth learning.

\section{Disposal of waste}

There exists lots of mining pollutant in coal mining wastelands such as PAHs, heavy metal pollutant and so on. It is the basis for landscape rebirth of coal mining wastelands to clarify the pollution and restore the ecology of the site. Different from the purely science of ecology restoration and environmental engineering, the ways landscape designers deal with pollutant tend to be more like strategy. The mainly methods are as follows.

\section{1) Method of entire removal}

This method applies to soil polluted less seriously. The polluted topsoil and other seriously polluted, poisonous and dangerous substances are usually entirely removed while deep soil and other less seriously polluted soil can be 
handled in other ways.

\section{2) Method of burying and covering}

The seriously polluted soil are generally improved through various ways of biotechnology, the conventional practice is to change the soil or cover something with soil. On the upside of polluted soil are covered with a layer of pitch which are then spread with new soil. Though the drainage facilities, the runoff discharged on the surface is collected through drainage facilities for fear of pollution expansion because of permeation of rain water.

\section{3) Method of natural reservation}

If wastelands have relatively small negative effect on environment or they start new ecological self-restoration, they can be let alone. In some suitable environmental areas, keeping pollutant and letting them keep on natural restoration will not only reduce investment but also preserve the variety and memory value.

In the design of North Duisburg Landscape Park in Germany, the designer Peter Latz had special thoughts and created the idea of "Garden + Pollutant + Site". He thought pollution and wastelands are a part of site, an industrial heritage which can be properly retained. For instance, in the process of natural restoration on the surface of waste many colorful plants grow up which can be preserved as a part of landscape.

\section{The transformation and reuse of abandoned pits}

The abandoned pits are man-made relics left after mining activities. Landscape designers have accumulated many methods through many years of exploration in transforming pits. The methods of pits transformation vary from the one of storing goods to transforming museums and archives, to tourist development, pits farming, reclamation and reuse of pits. Those ways adjusting to local conditions make pits - the abandoned resources regain their value.

\section{E. The plant landscape design}

As the element in landscaping, plants play a great role in landscape design of coal mining wastelands. On the one hand, pants can be the pioneer in improving soil and reforming renovating environment; on the other hand, plants can soften the hard landscapes such as buildings, structures and have the function of landscaping.

\section{$F$. The characteristic landscape construction in the site}

Coal mining wastelands are the important places where people can touch and know industrial history and culture. Here, people can see the change of the site, changes brought by human's activities, people's emotion on this place. Preservation and protection of typical landscape characteristics in coal mining wastelands and reduction of historical landscapes will not only show respect for the spirits of the site but also bring new characteristic landscape in the site.

In reconstruction of industrial wastelands, in some works designers often use bold and bright colors to create an active atmosphere. For instance, in North Duisburg Landscape Park huge concrete of stock bin are worked into climbing wall, scratches and grooves left on the wall after the knock and friction of minerals turn into natural anchors which can be used by mountain climbers. In some cases, designers build distinctive landscape atmosphere though light design and other ways.

\section{G. Lessons from Chinese classical garden design}

Abundant gardening ideas and methods have been accumulated in Chinese classical gardening culture with a long history. These methods not only have positive effect on contemporary garden landscapes, but also provide references for the special landscape-coal mining wastelands.

\section{1) The creation of artistic conception}

The artistic state of Chinese gardens is roughly divided into three levels: habit, picturesque scene, artistic conception. Chinese gardens not only create vital habit and picturesque scene but also artistic conception which can stir up people's feelings: their passion for romanticism and pursuit for idealism. All of this show the wisdom of designer of Chinese classical garden.

In reconstruction of wastelands those ways can be used properly, for example, people can move the scenes around the site with scenery frame and artistic concept into viewers' sight, which can function as view borrowing. There is another example, people will have associations for inscriptions and wall if they are associated with history and culture of the site; the artistic conception will be strengthened by the contrast of image, volume, direction, brightness, actual situation, color, texture and other sides of the landscape element.

\section{2) The application of traditional gardening skills}

There are distinctive ways and skills in Chinese traditional gardening which can be summarized as Rockery-Pile and Water-Scenery-Building, building management, flowers and trees allocation. Many of those skills act as references for coal mining wastelands reconstruction. The ancient Chinese garden designers paid great attention to constructing environmental landscape as they utilized and reconstructed nature. The traditional quarrying technique is combing quarrying with landscaping and reconstructing and taking advantage of deserted stone pits in the mountain landscape, this method still give inspiration for today's scene district program. Besides, Chinese traditional landscaping skills such as opposite scenery, obstructive scenery, framed scenery, leaking scenery, vista line, dividing, scenery, adding scenery, borrowed scenery can all be used into the landscape reconstruction of coal mining wastelands according to local conditions.

\section{CONCLUSION}

At the present, the fast development of coal-mining industry ensures the resources for national economical development, but as the mineral resources gradually dry up, large number of coal mining wastelands arise. As a result, they bring about a series of environmental and social problems in coal miming cities, making bad effect on ecological environment, causing a variety of landscape problems which lead to the decline of people's living quality 
in mining areas and hinder the urban development. It is the purpose of landscape design study of coal mining wastelands to guarantee the residents' living environment in the mining area, preserve the urban history and develop the characteristics of mining cities to construct wasteland landscape with characteristics. The reuse of coal mining wastelands will be a long and complex project which involves wide professional fields. There is hope that in the project of the reuse of the collapsed place of mining areas, when governed, it can follow the trend of ecological city construction, perfect the urban ecosystem as a whole and coordinate development between urban and rural areas.

\section{REFERENCES}

[1] Feng Guobao et al. Governance and Ecological Restoration of Abandoned Coal Mine Area $[\mathrm{M}]$. Beijing: China Agriculture Press, 2009.12

[2] Ma Hang, Song Jusheng, Dai Donghui. Strategy and Practice about Renovation and Reconstruction of Western Abandoned Industrial Zone [M]. Beijing: Science Press, 2014.3

[3] Zhang Jingcheng, Liu Liyong, Liu Guangyu. Protection and Utilization of Industrial Heritage: with the Perspective of "Creative Economy" [M]. Beijing: Peking University Press. 2013.1 